\title{
Video Article \\ Synthesis of Information-bearing Peptoids and their Sequence-directed Dynamic Covalent Self-assembly
}

\author{
Samuel C. Leguizamon ${ }^{1}$, Abdulla F. Alqubati ${ }^{1}$, Timothy F. Scott ${ }^{2,3}$ \\ ${ }^{1}$ Department of Chemical Engineering, University of Michigan \\ ${ }^{2}$ Department of Chemical Engineering, Monash University \\ ${ }^{3}$ Department of Materials Science and Engineering, Monash University
}

Correspondence to: Timothy F. Scott at timothy.scott@monash.edu

URL: https://www.jove.com/video/60442

DOI: doi:10.3791/60442

Keywords: Chemistry, Issue 156, self-assembly, dynamic covalent chemistry, peptoid, sequence-specific, molecular ladder, kinetic trapping, Lewis acid, supramolecular structures

Date Published: 2/6/2020

Citation: Leguizamon, S.C., Alqubati, A.F., Scott, T.F. Synthesis of Information-bearing Peptoids and their Sequence-directed Dynamic Covalent Self-assembly. J. Vis. Exp. (156), e60442, doi:10.3791/60442 (2020).

\section{Abstract}

This protocol presents the use of Lewis acidic multi-role reagents to circumvent kinetic trapping observed during the self-assembly of information-encoded oligomeric strands mediated by paired dynamic covalent interactions in a manner mimicking the thermal cycling commonly employed for the self-assembly of complementary nucleic acid sequences. Primary amine monomers bearing aldehyde and amine pendant moieties are functionalized with orthogonal protecting groups for use as dynamic covalent reactant pairs. Using a modified automated peptide synthesizer, the primary amine monomers are encoded into oligo(peptoid) strands through solid-phase submonomer synthesis. Upon purification by high-performance liquid chromatography (HPLC) and characterization by electrospray ionization mass spectrometry (ESI-MS), sequencespecific oligomers are subjected to high-loading of a Lewis acidic rare-earth metal triflate which both deprotects the aldehyde moieties and affects the reactant pair equilibrium such that strands completely dissociate. Subsequently, a fraction of the Lewis acid is extracted, enabling annealing of complementary sequence-specific strands to form information-encoded molecular ladders characterized by matrix assisted laser desorption/ionization mass spectrometry (MALDI-MS). The simple procedure outlined in this report circumvents kinetic traps commonly experienced in the field of dynamic covalent assembly and serves as a platform for the future design of robust, complex architectures.

\section{Video Link}

The video component of this article can be found at https://www.jove.com/video/60442/

\section{Introduction}

Progress in self-assembly, the process by which small sub-units generate larger architectures through thermodynamically-driven pathways, has afforded improved control over macro- and supra-molecular nanostructures typically by exploiting intermolecular interactions such as $\pi$-stacking and hydrogen bonding ${ }^{1,2,3,4}$. In particular, nucleic acids (i.e., polynucleotides) have emerged as remarkably versatile nano-construction media as the high information density provided by Watson-Crick base pairing permits the assembly of complex, sequence-selective structures ${ }^{4,5}$. Whereas the inherently low strength of these transient intermolecular bonds enables sub-unit rearrangement and error-correction, the resultant structures are often susceptible to thermal and mechanical degradation ${ }^{6}$. In contrast, dynamic covalent interactions ${ }^{7,8,9}$, a class of covalent bond-forming reactions that are reversible or rearrangeable under mild conditions and have recently been employed to yield intricate macromolecules such as ladders $^{10,11,12,13}$, cages $^{14,15,16}$, and stacks ${ }^{17}$, offer increased bond strengths and robust structures. Unfortunately, the capacity for rearrangement and error-checking is diminished by the relatively low rearrangement rates of these covalent species, curtailing their capacity for self-assembly into desired products ${ }^{18}$. To address this kinetic trapping, catalysts or harsh reaction conditions are often utilized in conjunction with simple building blocks. Here, we report a process which circumvents kinetic trapping to enable the self-assembly of molecular ladders from sequencespecific oligomers where the hybridization is directed by the information encoded in the oligomer residue sequences.

Given their synthetic accessibility, poly(N-substituted glycine)s (i.e., peptoids) are employed as the oligomeric precursors from which the molecular ladders are assembled $^{19}$. Peptoids are structural isomers of peptides in which pendant groups are affixed to the backbone-borne nitrogen instead of being coupled with the $\alpha$-carbon ${ }^{20}$. Using solid-phase synthesis, exact placement of dynamic covalent pendant groups along the peptoid chain is readily achieved, allowing for the design of precursor oligomers that can assemble into complex supramolecular structures ${ }^{21}$.

The dynamic covalent rearrangement of imine connectivity is employed in this procedure as the imine-generating condensation reaction provides a convenient means to characterize the self-assembly by mass spectrometry as each bond formed results in a mass reduction of $18 \mathrm{~g} / \mathrm{mol}^{22}$. Furthermore, the equilibrium between the amine and aldehyde reactants and imine product can be varied by altering the acid concentration. Specifically, rare-earth metal triflates are used to affect equilibrium, and additionally deprotect ethylene acetal-protected aldehydes ${ }^{23,24,25}$. To note, scandium triflate is already commonly used in the field of dynamic covalent self-assembly, including its recent success in aiding the synthesis of covalent organic frameworks (COFs) at room temperature ${ }^{26,27}$. Additionally, the contrasting solubility of the oligo(peptoid) 
sequences and the rare-earth metal triflate enables equilibrium control through liquid-liquid extraction. The process reported utilizes this control to circumvent the kinetic barriers preventing information-directed self-assembly.

\section{Protocol}

CAUTION: Several chemicals used in this protocol are corrosive, flammable or toxic and should only be used under a chemical fume hood. Please use appropriate personal protective equipment and consult all relevant safety data sheets (SDS) before use.

\section{Monomer synthesis}

NOTE: Primary amines were synthesized according to published approaches.

1. Synthesis of 4-(2-aminoethyl)-N-(allylcarbonyloxy)phenylamine (Npam) $)^{25,28}$

1. Add $5.0 \mathrm{~g}(36.7 \mathrm{mmol})$ of 4 -(2-aminoethyl)aniline to $150 \mathrm{~mL}$ of $10 \%$ acetic acid (aqueous solution, $\mathrm{v} / \mathrm{v})$. NOTE: The use of weak acid enables selective protection of the aromatic amine without affecting the aliphatic amine owing to the large difference in $\mathrm{p} K_{\mathrm{a}}$ value between the two groups.

2. Prepare a solution of $4.9 \mathrm{~g}(40.4 \mathrm{mmol} ; 1.1$ equiv. ) allyl chloroformate in $150 \mathrm{~mL}$ of 1,4-dioxane.

3. Combine the solutions in a $500 \mathrm{~mL}$ round bottom flask equipped with a magnetic stir bar and stir the reaction mixture at room temperature overnight.

4. To work up the reaction, dilute with $500 \mathrm{~mL}$ of deionized $(\mathrm{DI})$ water and wash with diethyl ether $\left(\mathrm{Et}_{2} \mathrm{O}, 300 \mathrm{~mL} \times 3\right)$. Discard the organic fractions.

5. Adjust the aqueous phase to $\mathrm{pH} 14$ by adding $2 \mathrm{M} \mathrm{NaOH}$ (aqueous solution), and extract with $\mathrm{Et}_{2} \mathrm{O}(150 \mathrm{~mL} \times 3)$.

6. Combine the organic fractions and wash with $\mathrm{DI}$ water $(150 \mathrm{~mL} \times 3)$.

7. Dry over $\mathrm{Na}_{2} \mathrm{SO}_{4}$, then filter.

8. Evaporate to dryness under reduced pressure.

9. Confirm the identity of the isolated product, Npam, by nuclear magnetic resonance (NMR) spectroscopy. Expect the following results: ${ }^{1} \mathrm{H} \mathrm{NMR}\left(500 \mathrm{MHz}, \mathrm{CdCl}_{3}\right) \delta: 7.31(\mathrm{~d}, J=8.0 \mathrm{~Hz}, 2 \mathrm{H}, \mathrm{Ar}), 7.14(\mathrm{~d}, J=8.5 \mathrm{~Hz}, 2 \mathrm{H}, \mathrm{Ar}), 6.65(\mathrm{~s}, 1 \mathrm{H},-\mathrm{NH}-), 6.04-5.89(\mathrm{~m}, 1 \mathrm{H},-$ $\left.\mathrm{CH}=\mathrm{CH}_{2}\right), 5.36(\mathrm{dq}, J=17.1,1.6 \mathrm{~Hz}, 1 \mathrm{H},-\mathrm{CH}=\mathrm{CHH}), 5.26(\mathrm{dq}, J=10.5,1.4 \mathrm{~Hz}, 1 \mathrm{H},-\mathrm{CH}=\mathrm{CH} H), 4.66\left(\mathrm{dt}, J=5.8,1.5 \mathrm{~Hz}, 2 \mathrm{H},-\mathrm{CH} 2^{-}\right.$ $\left.\mathrm{CH}=\mathrm{CH}_{2}\right), 2.94\left(\mathrm{t}, \mathrm{J}=6.8 \mathrm{~Hz}, 2 \mathrm{H},-\mathrm{CH}_{2}-\mathrm{NH}_{2}\right), 2.70\left(\mathrm{t}, \mathrm{J}=6.8 \mathrm{~Hz}, 2 \mathrm{H},-\mathrm{CH}_{2}-\mathrm{Ar}\right), 1.04\left(\mathrm{~s}, 2 \mathrm{H},-\mathrm{CH}_{2}-\mathrm{NH}_{2}\right) .{ }^{13} \mathrm{C} \mathrm{NMR}\left(125 \mathrm{MHz}, \mathrm{CD}_{3} \mathrm{OD}\right) \delta$ : $154.85,137.00,134.98,133.51,129.36,119.41,116.92,65.62,59.89,43.47,38.72$.

NOTE: The product is a light yellow solid and has an overall yield of $69 \%$. Use the product without further purification.

2. Synthesis of 4-(1,3-dioxacyclopent-2-yl)benzonitrile ${ }^{29,30}$

1. Dissolve $25 \mathrm{~g}(0.19 \mathrm{~mol})$ of 4-cyanobenzaldehyde in $200 \mathrm{~mL}$ of toluene.

2. Add $42.2 \mathrm{~mL}(0.768 \mathrm{mmol} ; 4$ equiv. $)$ of ethylene glycol and $0.02 \mathrm{~g}(0.1 \mathrm{mmol} ; 0.05 \mathrm{~mol} \%)$ of toluene-p-sulfonic acid to the reaction mixture.

3. Stir and reflux overnight at $120^{\circ} \mathrm{C}$ using a Dean-Stark trap (i.e., azeotropic distillation) to remove water generated during the reaction.

4. After the reaction is complete and cooled to room temperature, add $40 \mathrm{~mL}$ of $5 \% \mathrm{NaHCO}_{3}(\mathrm{w} / \mathrm{v})$ aqueous solution.

5. Extract the organic layer, and wash with DI water three times.

6. Dry over $\mathrm{Na}_{2} \mathrm{SO}_{4}$, then filter.

7. Evaporate to dryness under reduced pressure.

8. Confirm the identity of the isolated product, by NMR spectroscopy. Expect the following results: ${ }^{1} \mathrm{H} \mathrm{NMR}(400 \mathrm{MHz}, \mathrm{CDCl})_{3} \delta: 7.67(\mathrm{~d}$, $J=8.0,2 \mathrm{H}, \mathrm{Ar}), 7.59(\mathrm{~d}, J=8.4,2 \mathrm{H}, \mathrm{Ar}), 5.84(\mathrm{~s}, 1 \mathrm{H}, \mathrm{CH}), 4.12-4.03\left(\mathrm{AA}^{\prime} \mathrm{BB} ', 4 \mathrm{H},\left(\mathrm{CH}_{2} \mathrm{O}\right)_{2}\right) .{ }^{13} \mathrm{C} \mathrm{NMR}\left(100 \mathrm{MHz}, \mathrm{CDCl}_{3}\right) \delta: 143.20$, $132.34,127.30,118.72,113.02,102.56,65.57$

NOTE: The product is a white crystalline solid and has an overall yield of $86 \%$. Use the product without further purification.

3. Synthesis of 4-(1,3-dioxacyclopent-2-yl)benzylamine (Npal) ${ }^{29}$

1. Prepare a solution of $10 \mathrm{~g}(0.057 \mathrm{~mol})$ of 4-(1,3-dioxacyclopent-2-yl)benzonitrile in $100 \mathrm{~mL}$ of anhydrous $\mathrm{Et}_{2} \mathrm{O}$.

2. Carefully add $4.3 \mathrm{~g}(0.11 \mathrm{~mol} ; 2$ equiv. $)$ of $\mathrm{LiAlH}_{4}$ to $100 \mathrm{~mL}$ of anhydrous $\mathrm{Et}_{2} \mathrm{O}$ in a round bottom flask at $0{ }^{\circ} \mathrm{C}$. Stir to create a wellmixed suspension and seal the system under an inert atmosphere using an argon-filled balloon. Carefully quench with ethanol any residual $\mathrm{LiAlH}_{4}$ on equipment used for weighing.

CAUTION: Lithium aluminum hydride $\left(\mathrm{LiAlH}_{4}\right)$ is a mild pyrophore; handle under inert gas and protect from moisture.

3. Add the 4-(1,3-dioxacyclopent-2-yl)benzonitrile solution slowly using an addition funnel or a syringe pump while maintaining the reaction mixture at a temperature of $0{ }^{\circ} \mathrm{C}$.

4. Stir the reaction mixture for $4 \mathrm{~h}$ at $0{ }^{\circ} \mathrm{C}$, followed with $12 \mathrm{~h}$ at room temperature.

5. After the reaction is complete and cooled to $0{ }^{\circ} \mathrm{C}$, slowly add $95 \%$ ethanol $(30 \mathrm{~mL})$. Further quench by adding $50 \%$ ethanol in water $(\mathrm{v} /$ $\mathrm{v}, 20 \mathrm{~mL}$ ). A bubbler can be used to monitor the quenching process. NOTE: Add additional anhydrous $\mathrm{Et}_{2} \mathrm{O}$ as needed to maintain an adequate stirring rate.

6. Separate the ether supernatant and evaporate to dryness under reduced pressure.

7. Filter the resultant oil through a $0.45 \mu \mathrm{m}$ syringe filter.

8. Confirm the identity of the isolated product, Npal, by NMR spectroscopy. Expect the following results: ${ }^{1} \mathrm{H} \mathrm{NMR}(400 \mathrm{MHz}, \mathrm{CDCl})_{3} \delta$ : $7.44(\mathrm{~d}, J=8,2 \mathrm{H}, \mathrm{Ar}), 7.32(\mathrm{~d}, J=8,2 \mathrm{H}, \mathrm{Ar}), 5.80(\mathrm{~s}, 1 \mathrm{H}, \mathrm{CH}), 4.14-4.0\left(\mathrm{AA}^{\prime} \mathrm{BB}\right.$ ', 4H, $\left.\left(\mathrm{CH}_{2} \mathrm{O}\right)_{2}\right), 3.87\left(\mathrm{~s}, 2 \mathrm{H},-\mathrm{CH}_{2}-\mathrm{NH}_{2}\right){ }^{13} \mathrm{C} \mathrm{NMR}^{\mathrm{N}}$ $\left(100 \mathrm{MHz}, \mathrm{CDCl}_{3}\right) \delta: 144.53,136.53,127.16,126.77,103.72,65.39,46.35$.

NOTE: The product is a yellow oil and has an overall yield of $70 \%$. Use the product without further purification.

4. Synthesis of 2-(2-ethoxyethoxy)ethyl tosylate (29,31 $^{2}$

1. Add $20 \mathrm{~g}(0.15 \mathrm{~mol})$ of diethylene glycol monoethyl ether and $50 \mathrm{~mL}$ of tetrahydrofuran (THF) to a $250 \mathrm{~mL}$ round bottom flask with a magnetic stirrer.

2. Cool to $0{ }^{\circ} \mathrm{C}$ and seal the system under an inert atmosphere using an argon-filled balloon. 
3. Add $50 \mathrm{~mL}$ of $6 \mathrm{M}$ aqueous $\mathrm{NaOH}$ (2 equiv.).

4. Dissolve $54 \mathrm{~g}(0.28 \mathrm{~mol} ; 2$ equiv. $)$ of tosyl chloride in $80 \mathrm{~mL}$ of THF and add the solution to the reaction mixture dropwise. Stir for $1 \mathrm{~h}$ at $0{ }^{\circ} \mathrm{C}$.

5. Allow the reaction mixture to reach room temperature and stir for another hour.

6. Extract the reaction mixture with $\mathrm{Et}_{2} \mathrm{O}(400 \mathrm{~mL})$.

7. Wash the organic layer with $1 \mathrm{M} \mathrm{NaOH}$, then with DI water.

8. Dry over $\mathrm{Na}_{2} \mathrm{SO}_{4}$, then filter.

9. Evaporate to dryness under reduced pressure.

10. Confirm the identity of the isolated product by NMR spectroscopy. Expect the following results: ${ }^{1} \mathrm{H} \mathrm{NMR}(400 \mathrm{MHz}, \mathrm{CDCl} 3) \delta: 7.78(\mathrm{~d}$, $J=8.0,2 \mathrm{H},-\mathrm{S}-\mathrm{C}=\mathrm{CH}-\mathrm{CH}), 7.33(\mathrm{~d}, J=8.5,2 \mathrm{H},-\mathrm{S}-\mathrm{C}=\mathrm{CH}-\mathrm{CH}), 4.15\left(\mathrm{t}, J=5.0,2 \mathrm{H},-\mathrm{CH}_{2}-\mathrm{CH}_{2}-\mathrm{O}-\mathrm{Ts}\right), 3.68\left(\mathrm{t}, J=5.0,2 \mathrm{H}, \mathrm{CH}-\mathrm{CH} \mathrm{H}_{2}-\mathrm{O}-\right.$ $\mathrm{Ts}), 3.60-3.42\left(\mathrm{~m}, 6 \mathrm{H}, \mathrm{O}-\mathrm{CH}_{2}-\mathrm{CH}_{2}-\mathrm{O}-\mathrm{CH}_{2}-\mathrm{CH}_{3}\right), 2.43\left(\mathrm{~s}, 3 \mathrm{H}, \mathrm{C}-\mathrm{CH}_{3}\right), 1.17\left(\mathrm{t}, \mathrm{J}=7.0,3 \mathrm{H}, \mathrm{O}-\mathrm{CH}_{2}-\mathrm{CH}_{3}\right) .{ }^{13} \mathrm{C} \mathrm{NMR}(100 \mathrm{MHz}, \mathrm{CDCl} 3) \delta$ : $144.79,132.95,130.26,129.80,127.90,126.95,70.75,69.68,69.29,68.61,66.57,21.56,15.11$.

NOTE: The product is a colorless liquid and has an overall yield of $98 \%$. Use the product without further purification.

5. Synthesis of 2-(2-ethoxyethoxy)ethyl azide ${ }^{29,31}$

1. Dissolve $40 \mathrm{~g}(0.14 \mathrm{~mol})$ of 2-(2-ethoxyethoxy)ethyl tosylate in $250 \mathrm{~mL}$ of dimethylformamide (DMF) in a round bottom flask with a magnetic stirrer. Seal the system under an inert atmosphere using an argon-filled balloon.

2. Add $32 \mathrm{~g}(0.49 \mathrm{~mol} ; 3.5$ equiv. $)$ of $\mathrm{NaN}_{3}$ to the reaction mixture.

CAUTION: Do not use a metal spatula when weighing $\mathrm{NaN}_{3}$. $\mathrm{NaN}_{3}$ may react with lead and copper which results in the formation of highly explosive metal azides. It is acutely toxic and fatal if swallowed or in contact with skin.

3. Heat the reaction mixture to $60{ }^{\circ} \mathrm{C}$ and let it run for $36 \mathrm{~h}$. Then cool to room temperature.

4. Dilute with large amount of water $(500 \mathrm{~mL})$ and extract with $\mathrm{Et}_{2} \mathrm{O}(150 \mathrm{~mL} \times 3)$.

5. Isolate the organic layer and perform water washes.

6. Dry over $\mathrm{Na}_{2} \mathrm{SO}_{4}$, then filter.

7. Evaporate to dryness under reduced pressure.

8. Confirm the identity of the isolated product by NMR spectroscopy. Expect the following results: ${ }^{1} \mathrm{H} \mathrm{NMR}(400 \mathrm{MHz}, \mathrm{CDCl}) \delta: 3.64(\mathrm{~m}$, $\left.4 \mathrm{H}, \mathrm{O}-\mathrm{CH}_{2}-\mathrm{CH}_{2}-\mathrm{O}\right), 3.58\left(\mathrm{~m}, 2 \mathrm{H}, \mathrm{N}_{3}-\mathrm{CH}_{2}-\mathrm{CH}_{2}-\mathrm{O}\right), 3.51$ (q, $\left.J=7.5,2 \mathrm{H}, \mathrm{O}-\mathrm{CH}_{2}-\mathrm{CH}_{3}\right), 3.38$ (t, $\left.J=5.0,2 \mathrm{H}, \mathrm{N}_{3}-\mathrm{CH}_{2}-\mathrm{CH}_{2}-\mathrm{O}\right), 1.19(\mathrm{t}, J=$ $\left.7.5,3 \mathrm{H}, \mathrm{O}-\mathrm{CH}_{2}-\mathrm{CH}_{3}\right) .{ }^{13} \mathrm{C}$ NMR $\left(100 \mathrm{MHz}, \mathrm{CDCl}_{3}\right) \delta: 70.70,69.97,69.80,66.63,50.60,15.08$.

NOTE: The product is a yellow liquid and has an overall yield of $85 \%$. Use the product without further purification.

6. Synthesis of 2-(2-ethoxyethoxy)ethylamine (Neee) $)^{29,31}$

1. Dissolve $20 \mathrm{~g}(0.13 \mathrm{~mol})$ of 2-(2-ethoxyethoxy)ethyl azide in $160 \mathrm{~mL}$ of THF in a $500 \mathrm{~mL}$ round bottom flask with a magnetic stirrer.

2. Add $40 \mathrm{~g}(0.15 \mathrm{~mol}, 1.1$ equiv.) of triphenylphosphine and stir overnight at room temperature under argon.

3. Quench the reaction mixture with water $(220 \mathrm{~mL})$ and allow it to stir for another day.

4. Wash the resulting solution with toluene, followed by dichloromethane (DCM).

5. Evaporate the aqueous layer under vacuum.

6. Confirm the identity of the isolated product, Neee, by NMR spectroscopy. Expect the following results: ${ }^{1} \mathrm{H} \mathrm{NMR}(400 \mathrm{MHz}, \mathrm{CDCl})_{3} \delta$ : 3.62-3.42 (m, 8H, NH $\left.\mathrm{NH}_{2}-\mathrm{CH}_{2}-\mathrm{CH}_{2}-\mathrm{O}-\mathrm{CH}_{2}-\mathrm{CH}_{2}-\mathrm{O}-\mathrm{CH}_{2}-\mathrm{CH}_{3}\right), 2.82\left(\mathrm{~m}, 2 \mathrm{H}, \mathrm{NH}_{2}-\mathrm{CH}_{2}-\mathrm{CH}_{2}-\mathrm{O}\right), 1.48(\mathrm{~s}, 2 \mathrm{H}, \mathrm{NH}), 1.16(\mathrm{t}, J=7.5,3 \mathrm{H}, \mathrm{O}-$ $\left.\mathrm{CH}_{2}-\mathrm{CH}_{3}\right) .{ }^{13} \mathrm{C} \mathrm{NMR}\left(100 \mathrm{MHz}, \mathrm{CDCl}_{3}\right) \delta: 73.14,70.72,69.64,66.45,41.35,15.00$.

NOTE: The product is a yellow liquid and has an overall yield of $58 \%$. Use the product without further purification.

\section{Solid-phase submonomer synthesis of oligo(peptoids)}

NOTE: The submonomer approach to solid-phase synthesis (SPS) was employed as it enables the production of sequence-specific oligomers with high coupling efficiency. An automated peptide synthesizer was adapted to rapidly generate oligo(peptoids). Settings may require modification for different instrumentation.

\section{Preparation}

1. Weigh $0.125 \mathrm{~g}$ of Fmoc-Photolabile SS resin $(0.8 \mathrm{mmol} / \mathrm{g}$ typical loading, $0.1 \mathrm{mmol}$ scale, $100-200 \mathrm{mesh}, 1 \%$ DVB) and add to a fritted automated synthesizer reaction vessel. Insert the vessel into the microwave portion of the synthesizer.

2. Fill the main solvent bottle with DMF and the deprotection bottle with $20 \% 4$-methylpiperidine in DMF (v/v). Empty waste.

3. Prepare $1 \mathrm{M}$ solutions of bromoacetic acid and $\mathrm{N}, \mathrm{N}^{\prime}$-diisopropylcarbodiimide (DIC) in DMF with total volumes of $1.5 \mathrm{~mL} \times(\mathrm{number}$ of residues in sequence) $+5 \mathrm{~mL}$. The extra $5 \mathrm{~mL}$ ensures that no air enters the machine. Add $0.47 \mathrm{~mL}$ of acetic anhydride to DMF to make a $5 \mathrm{~mL}$ capping solution.

CAUTION: DIC can cause serious eye damage, skin irritation and sensitization, and respiratory irritation and sensitization.

4. Prepare $0.5 \mathrm{M}$ solutions of each primary amine (Npam, Npal, Neee, and Nma (2-methoxyethylamine)) in N-methyl-2-pyrrolidone (NMP) used for the displacement step. Total volumes of the primary amine solutions should be $2.5 \mathrm{~mL} \times$ (number of residues of the appropriate primary amine) $+2.5 \mathrm{~mL}$.

5. Add all solutions to the automated synthesizer manifold.

\section{Synthesis}

NOTE: Perform using an automated peptide synthesizer.

1. Swell the resin at room temperature for $5 \mathrm{~min}$ with $10 \mathrm{~mL}$ of DMF. Drain the reaction vessel.

2. Cleave the Fmoc group with $3 \mathrm{~mL}$ of the $20 \% 4$-methylpiperidine solution for $30 \mathrm{~s}$ at $75^{\circ} \mathrm{C}$ and $90 \mathrm{~s}$ at $90{ }^{\circ} \mathrm{C}$. Drain the vessel. Repeat. Wash with DMF $(2 \mathrm{~mL} \times 2)$.

3. Add to the vessel $1.5 \mathrm{~mL}$ of the bromoacetic acid solution and $1.5 \mathrm{~mL}$ of the DIC solution. Heat the reaction at $75^{\circ} \mathrm{C}$ for $4.5 \mathrm{~min}$ to perform the bromoacetylation reaction. Wash the resin $(5 \mathrm{~mL}$ of DMF $\times 3$ ).

4. Perform the displacement reaction by addition of $2.5 \mathrm{~mL}$ primary amine monomer solution to the reaction vessel. Heat at $75{ }^{\circ} \mathrm{C}$ for 4.5 min. Wash resin $(5 \mathrm{~mL}$ of $\mathrm{DMF} \times 3)$. 
5. Repeat steps 2.2.3. and 2.2.4. while sequentially substituting the primary amine monomer used in step 2.2.4. to grow oligo(peptoid) chain in a sequence-specific manner.

6. After the final displacement step, cap the sequence by adding $2.5 \mathrm{~mL}$ of the acetic anhydride solution and $2 \mathrm{~mL}$ of the DIC solution. Heat at $50^{\circ} \mathrm{C}$ for $2 \mathrm{~min}$. Wash the resin ( $5 \mathrm{~mL}$ of DMF $\left.\times 6\right)$.

7. Transfer the resin to a fritted glass reaction vessel equipped with a 3-way stopcock. The glass reaction vessel should be previously siliconized to prevent beads from adhering to the walls. Silanize the walls by filling the vessel with a $5 \%$ dichlorodimethylsilane in dichloroethane (DCE) (v/v) solution to the top and letting it sit for 30 min. Drain the vessel and wash with DCE and methanol. Dry glass vessel before use.

8. Wash the resin with $\mathrm{DCM}(5 \mathrm{~mL} \times 3)$, bubbling with $\mathrm{N}_{2}$ through one arm and pulling vacuum with another.

9. Dry and store resin and attached oligo(peptoid) until deprotection and cleavage.

3. Alloc-amine deprotection and cleavage from resin

1. If the resin has been stored for more than a day, reswell the resin by bubbling with $5 \mathrm{~mL}$ of DMF for 10 min. Then drain the vessel and add a small magnetic stir bar.

2. Add $3 \mathrm{~mL}$ of dry DCM to the glass peptide vessel.

3. Weigh 0.1 equivalents of tetrakis(triphenylphosphine)palladium( 0 ) and 25 equivalents of phenylsilane per Alloc-group. Use a clamp to position the reaction vessel at an angle above a stir plate such that the resin undergoes gentle agitation while remaining suspended in the solvent. To prevent the DCM from evaporating, cap the reaction vessel.

4. After $1 \mathrm{~h}$, filter off the solution and wash the resin with DCM $(3 \times 5 \mathrm{~mL})$.

5. Repeat steps 2.3.2. and 2.3.3.

6. Rinse the resin sequentially with methanol and DCM twice.

7. Transfer the resin and magnetic stir bar to a $20 \mathrm{~mL}$ vial.

8. Submerge the resin in DMF, stir, and cleave under irradiation for $36 \mathrm{~h}$ at approximately $25 \mathrm{~mW}_{\mathrm{cm}} \mathrm{cm}^{-2}$ with $405 \mathrm{~nm}$. A small portion of resin can be cleaved and characterized in ESI-MS before this step to ensure complete Alloc deprotection of amine. If any Alloc groups remain, repeat steps 2.3.2 and 2.3.3.

9. Separate liberated oligo(peptoid) from resin via a syringe filter. Remove solvent under vacuum.

4. Purification and characterization of oligo(peptoids)

1. Reconstitute the peptoids in a 50/50 mixture of water/acetonitrile.

2. Purify with reverse-phase preparative HPLC (C18). Combine purified fractions, freeze, and lyophilize to yield off-white powder. The powder can be stored for further use.

3. Analyze with ESI-MS after purification.

4. Perform MALDI mass spectrometry in reflectron positive ion mode. Mix $2 \mu \mathrm{L}$ of a solution of the sample $(1 \mathrm{mM})$ with $6 \mu \mathrm{L}$ of a mixture of $10 \mathrm{mg}$ of matrix [2-(4-hydroxyphenylazo)benzoic acid (HABA)] in $200 \mu \mathrm{L}$ of acetonitrile. Spot on a MALDI sample plate and allow to air dry.

5. For purity, perform analytical HPLC of purified oligo(peptoids).

\section{Sequence-selective ladder self-assembly}

\section{Self-assembly through dissociation/extraction/annealing}

1. Prepare $10 \mathrm{mM}$ stock solutions of each oligo(peptoid) sequence used for self-assembly and a $10 \mathrm{mM}$ stock solution of scandium triflate $\left(\mathrm{Sc}(\mathrm{OTf})_{3}\right)$ in anhydrous acetonitrile.

2. To a $3 \mathrm{~mL}$ vial equipped with a magnetic stir bar, add $20 \mu \mathrm{L}$ of each peptoid stock solution. Add 1.5 eq of Sc(OTf) 3 per potential imine bond from the stock solution. Add enough water and acetonitrile to form a $200 \mu \mathrm{L} 2 \%(\mathrm{v} / \mathrm{v})$ of water/acetonitrile solution total.

3. Stir gently at $70{ }^{\circ} \mathrm{C}$ for $2 \mathrm{~h}$ for acetal-deprotection of the aldehyde and dissociation of all strands.

4. Charge the vial with $200 \mu \mathrm{L}$ of chloroform and $2 \mathrm{~mL}$ of water. Shake gently.

5. Allow the mixture to stand (at least $15 \mathrm{~min}$ ) and, upon complete phase separation, extract the organic layer with a microliter syringe.

6. Stir in a new vial at $70{ }^{\circ} \mathrm{C}$ for oligomer annealing, typically $6 \mathrm{~h}$. Ladder hybridization can also be performed at room temperature but over a longer period.

\section{Characterization of self-assembled species}

1. Perform MALDI-TOF mass spectrometry on the reaction mixture solutions after steps 3.1.3., 3.1.5., and 3.1.6. to monitor the reaction. If hybridization is incomplete, add 1.5 eq of $\mathrm{Sc}(\mathrm{OTf})_{3}$ per potential imine bond from the stock solution and repeat steps 3.1.3-3.1.6. until complete.

2. Dry the sample under a steady stream of nitrogen and reconstitute in $1 \mathrm{~mL}$ of $2 \%$ nitric acid (aqueous solution, v/v). Dilute $4 \times 10^{6}$-fold with HPLC water. Determine post-extraction scandium concentration with inductively coupled plasma mass spectrometry (ICP-MS).

\section{Representative Results}

To demonstrate the ability of information-encoded peptoids to undergo sequence-selective dynamic covalent self-assembly into molecular ladders, a representative strand, $\mathrm{H}_{2} \mathrm{~N}$-[Npam-Neee-Npal-Neee ${ }_{2}-\mathrm{Npam}-\mathrm{Nma}$, was synthesized and hybridized with its complementary peptoid sequence. The monomers Npam and Npal (characterized by ${ }^{1} \mathrm{H}$ NMR $(500 \mathrm{MHz})$, Figure 1) were employed as dynamic covalent reactant pairs with Neee aiding solubility of final self-assembled products. Additionally, the incorporation of the commercially available Nma monomer enables a mass differentiation between the two complementary sequences. Upon completion of the solid-phase submonomer synthesis, the Alloc-group was removed with $\mathrm{Pd}\left(\mathrm{PPh}_{3}\right)_{4}$. Prior to and after deprotection, portions of the resin were cleaved under $405 \mathrm{~nm}$ light and characterized by ESIMS (Figure 2). The sequence was purified by prep HPLC, lyophilized to achieve an off-white powder, and purity confirmed with analytical HPLC 
(Figure 3). The oligo(peptoid) was subsequently hybridized with its complementary sequence, $\mathrm{H}_{2} \mathrm{~N}-[\mathrm{Npal}-\mathrm{Neee-Nam-Neee}]_{2}-\mathrm{Npal}$, to afford an in-registry ladder confirmed by MALDI-MS (Figure 4).
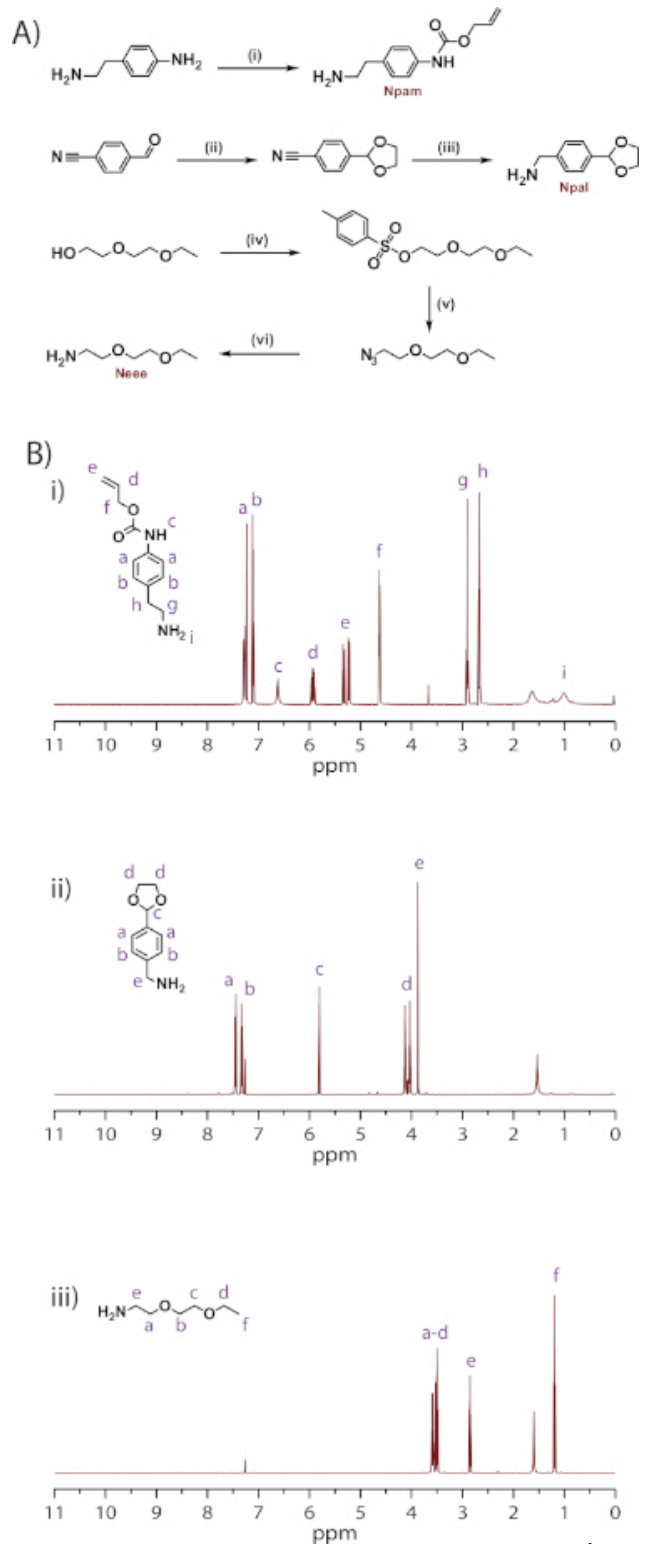

Figure 1: Monomer synthetic schemes and ${ }^{1}$ H-NMR spectra. (A) Monomer synthetic schemes with reagents and conditions: (i) allyl chloroformate, $10 \%$ aqueous acetic acid, 1,4-dioxane, room temperature, overnight; (ii) ethylene glycol, toluene-p-sulfonic acid, toluene, reflux, overnight; (iii) $\mathrm{LiAlH}_{4}$, anhydrous $\mathrm{Et}_{2} \mathrm{O}, 0{ }^{\circ} \mathrm{C}$ for $4 \mathrm{~h}$ then room temperature for $12 \mathrm{~h}$; (iv) tosyl chloride, THF, $0{ }^{\circ} \mathrm{C} ;(\mathbf{v}) \mathrm{NaN}$, DMF, $60{ }^{\circ} \mathrm{C}, 36 \mathrm{~h}$; (vi) triphenylphosphine, THF, overnight. (B) Monomer ${ }^{1} \mathrm{H}-\mathrm{NMR}$ spectra $\left(500 \mathrm{MHz}, \mathrm{CDCl}_{3}\right)$ : (i) 4-(2-aminoethyl)-N-(allylcarbonyloxy)phenylamine (Npam); (ii) 4-(1,3-dioxacyclopent-2-yl)benzylamine (Npal); (iii) 2-(2-ethoxyethoxy)ethylamine (Neee). Please click here to view a larger version of this figure. 

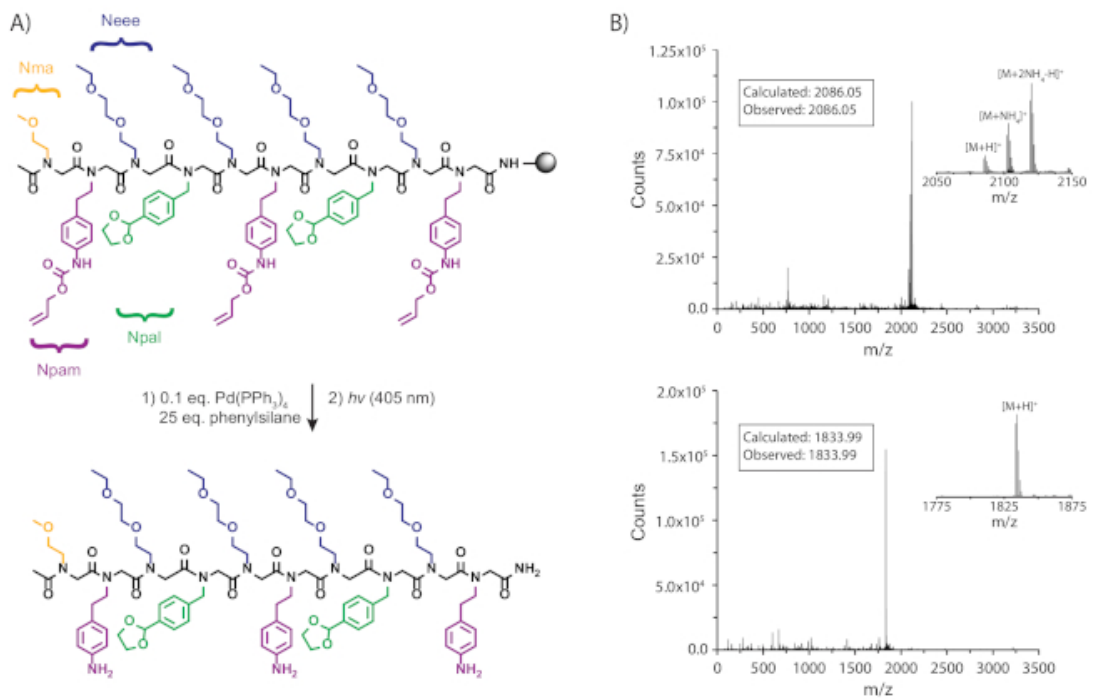

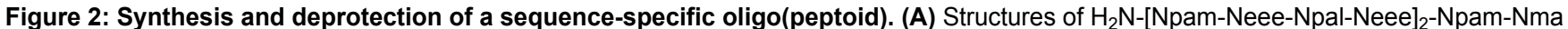
before and after Alloc-protecting group removal with accompanying (B) ESI mass spectrum. Please click here to view a larger version of this figure. 
A)

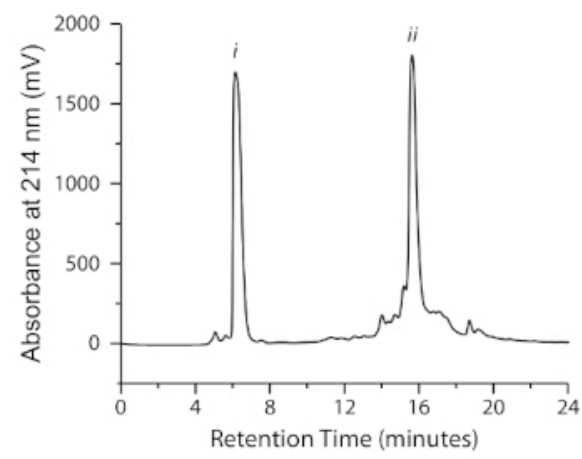

B)

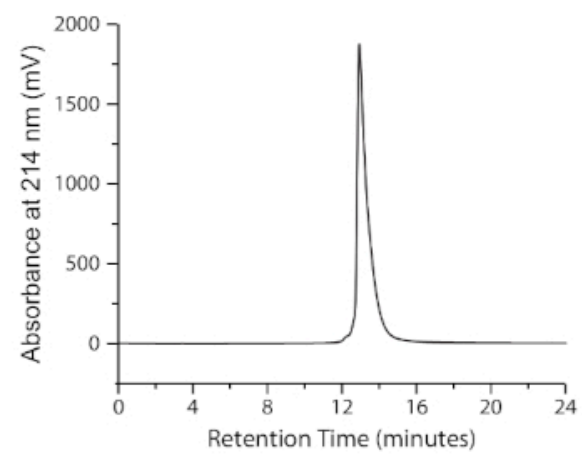

C)

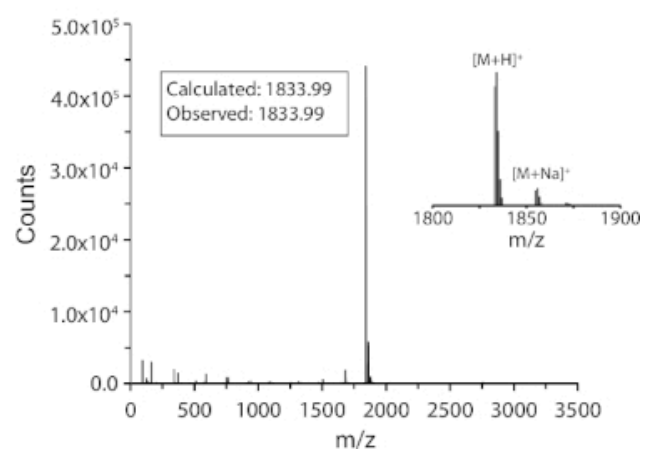

Figure 3: Purification and characterization of an information-encoded peptoid. (A) HPLC chromatogram of the strand purification by preparative HPLC with a linear gradient of acetonitrile (MeCN) and water: (1) 30\% MeCN, 0.1-2.1 min; (2) 30-95\% MeCN, 2.1-16.1 min; (3) 95\% $\mathrm{MeCN}, 16.1-23.1 \mathrm{~min}$; (4) 95\% MeCN, 23.1-26.1 min. Peaks $i$ and ii correspond to low molecular weight reaction by-products, primarily DICurea, and oligomeric species including the desired product, respectively. (B) Analytical HPLC chromatogram and (C) ESI mass spectrum of $\mathrm{H}_{2} \mathrm{~N}$ [Npam-Neee-Npal-Neee $]_{2}-\mathrm{Npam}-\mathrm{Nma}$ after lyophilization. Please click here to view a larger version of this figure. 


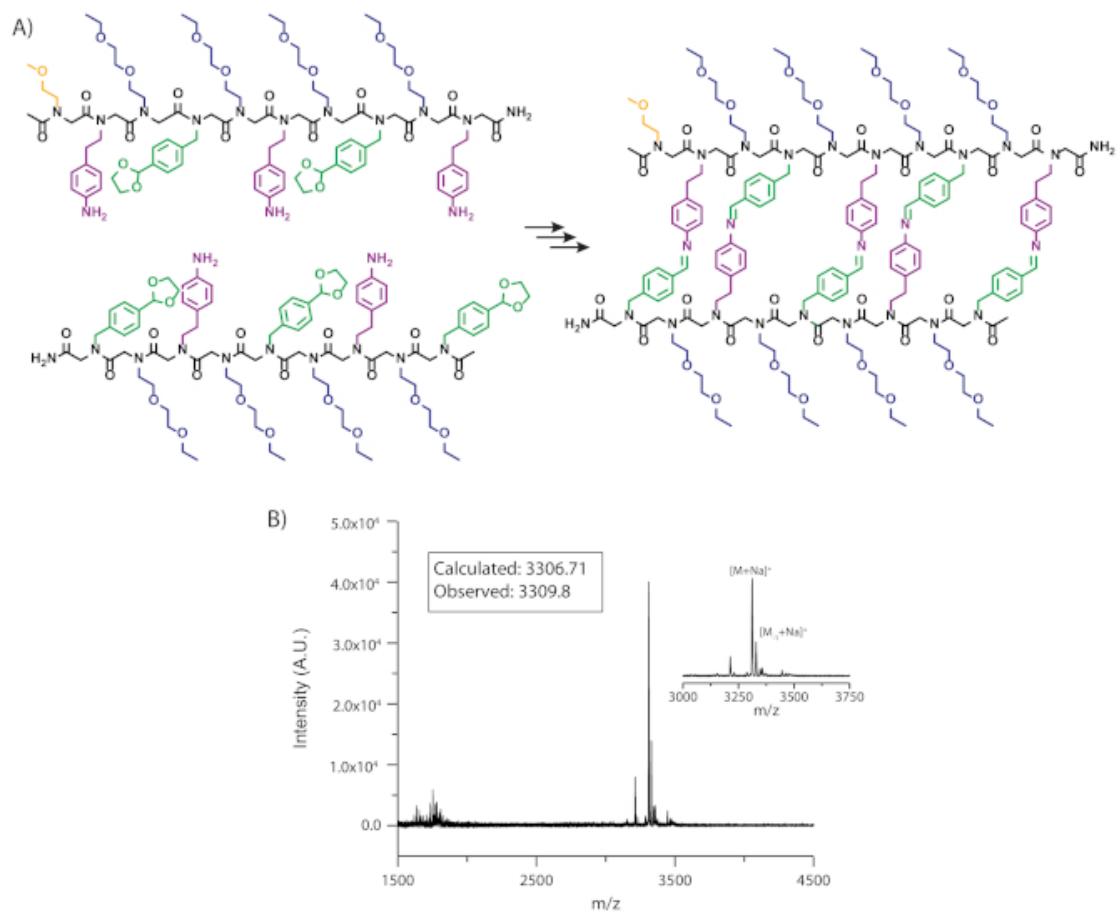

Figure 4: Self-assembly of $\mathrm{H}_{2} \mathrm{~N}$-[Npam-Neee-Npal-Neee ${ }_{2}$-Npam-Nma and its complementary sequence, $\mathrm{H}_{2} \mathrm{~N}-[\mathrm{Npal}-\mathrm{Neee}-\mathrm{Nam}-\mathrm{Neee}]_{2}-$ Npal. (A) Structures of the two sequences and the resulting sequence-driven assembly. (B) MALDI mass spectrum of the molecular ladder

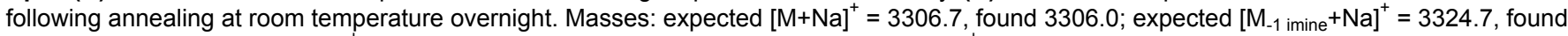
3323.9; expected $\left[\mathrm{M}_{-2} \text { imine }+\mathrm{Na}\right]^{+}=3342.7$, found 3342.8; expected $\left[\mathrm{M}_{-2} \text { imine }+\mathrm{CH}_{3} \mathrm{OH}+\mathrm{H}\right]^{+}=3352.8$, found 3352.0. Please click here to view a larger version of this figure.

\section{Discussion}

The technique herein describes the dynamic covalent assembly of information-bearing peptoid oligomers, where information is encoded in the sequence of their pendant groups. The use of an Alloc-protected amine monomer in conjunction with an ethylene acetal-protected aldehyde monomer allows for orthogonal deprotection, enabling Alloc deprotection on bead and acetal deprotection in situ during the self-assembly reaction, thereby ensuring the synthesized sequences do not prematurely react prior to oligomer purification and characterization. Importantly, the solid-phase synthesis is performed using a photolabile resin to enable oligomer cleavage from the bead under UV or violet light irradiation, precluding premature deprotection of the acid-labile, ethylene acetal-based protecting group. Several alternative deprotection schemes might be considered. For example, we initially employed dual acid-labile protecting groups (Boc-amine and ethylene acetal-aldehyde) with the intention of in situ deprotection by a strong acid followed with neutralization to allow the self-assembly reaction to proceed; however, this approach resulted in the immediate generation of precipitate upon addition of base. Alternatively, protection of the amine with a photolabile protecting group, 2-(2nitrophenyl)propoxycarbonyl (NPPOC), was envisioned as the aldehyde could be selectively deprotected upon treatment with trifluoroacetic acid (TFA) prior to purification. Unfortunately, in situ photolysis of the protecting group with UV light did not afford quantitative deprotection, even in the presence of photosensitizers and after extended irradiation periods ${ }^{25}$. Trimethylsilylethoxycarbonyl (i.e., Teoc) can be employed as an amine protecting group and is subject to cleavage upon treatment with rare-earth metal triflates; however, quantitative Teoc deprotection requires much higher rare-earth metal triflate loadings than that necessary for ethylene acetal deprotection. For this protocol, Teoc-amines may be used, but the Lewis acid concentration must be adjusted accordingly as sub-quantitative amine deprotection could prove problematic for larger self-assembled structures. Aliphatic functional groups were briefly considered, but deprotection of aliphatic aldehydes requires harsh conditions that truncate peptoid sequences $^{32,33}$.

Incorporation of Neee and Nma as inert spacer residues serve to improve oligomer solubility and enable facile mass-tagging of the precursor oligomers to afford ready identification of the generated species by mass spectroscopy. Furthermore, given the ' $\Sigma$-strand' conformation of peptoids where adjacent backbone segments adopt opposing rotational states to form a linear, twist-free oligomer ${ }^{34,35}$, sequences incorporating alternating dynamic covalent and inert spacer residues facilitates a structure in which reactive pendant groups are oriented in the same direction. Given the versatility of the submonomer method, a large and diverse library of primary amines can be employed to further modify the peptoid oligomers but may require adjustments to the protocol to maintain high coupling efficiency.

Whereas oligo(peptoids) can be synthesized manually in a glass reaction vessel ${ }^{19}$, automation of the process decreases the time for each residue addition from several hours to half an hour. Additionally, automation diminishes the quantity of monomer and wash solvent waste, particularly desirable when using primary amine monomers that are not commercially available. Although Alloc cleavage from the protectedamine residues is an efficient reaction, palladium oxidation can result in incomplete deprotection. Consequently, it is suggested to test cleave a portion of the resin and characterize the extent of deprotection with ESI-MS. For test cleavages, 30 min under $405 \mathrm{~nm}$ irradiation releases 
sufficient peptoid for mass spectrometry. Partial deprotection can be limited with the use of anaerobic conditions or repeating the deprotection reaction.

Whereas this article focuses on $\mathrm{Sc}(\mathrm{OTf})_{3}$ as a multi-role reagent, other rare-earth metal triflates, such as ytterbium triflate, have been shown to successfully mediate the information-directed assembly of molecular ladders. Notably, $\mathrm{Sc}(\mathrm{OTf})_{3}$ is the most Lewis acidic of the rare-earth metal triflates; thus, owing to the reduced catalytic ability afforded by other rare-earth metal triflates ${ }^{24,36}$, greater equivalents may be required to effect complete ethylene acetal deprotection and strand dissociation. The number of equivalents required can be determined with MALDI mass spectrometry by observing point at which strands completely dissociate. Dissociation is critical in the self-assembly process and is analogous to the melting of nucleic acid strands at raised temperature. The subsequent extraction of catalyst enables the formation and disruption of dynamic covalent pairings propelling the assembly of sequence-specific duplexes. This gradual annealing of the oligomeric strands circumvents the kinetic trapping (which, for molecular ladders, can yield out-of-registry species or incorrectly pair sequences) experienced by other methods.

Chloroform is an excellent solvent as phase separation in the chloroform/acetonitrile/water ternary system used here promotes the partial extraction of Lewis acid without resulting in precipitation of self-assembled structures ${ }^{37}$. Additionally, chloroform is one of the few solvents that promotes imine formation while maintaining molecular ladder solubility. Trace amounts of out-of-registry and incorrectly paired duplexes can often be observed owing to the dynamic nature of the system. Although this system is largely unaffected by small variation in rare-earth metal triflate concentrations upon extraction, on occasion, insufficient catalyst extraction generates a significant portion of incomplete hybridization and non-specific oligomer couplings. In this case, it is generally preferable to first re-dissociate with a further 1.5 equivalents of catalyst and then extract a second time rather than to re-extract immediately, as the complete dissociation of single strands is vital to the process. To simultaneously assemble several unique information-encoded molecular ladders, it may be necessary to increase the concentration of the rareearth metal triflate stock solution used to maintain equivalents and total reaction volume.

While these self-assemblies are primarily characterized by mass spectrometry, other techniques including fluorescence resonance energy transfer (FRET) are possible. Limitations include quantity of material necessary, affordability of monomers, and signal-to-noise ratio. Techniques requiring solvents, such as ${ }^{1} \mathrm{H}$ NMR, can additionally suffer from insolubility of self-assembled structures. Furthermore, rare-earth metal triflate concentrations post-extraction can be determined through such methods as ICP-MS or ${ }^{19} \mathrm{~F}$ NMR with an internal standard.

As progress towards improved control over macro- and supra-molecular nanostructures and materials proceeds, the challenge of designing and fabricating regular, but modifiable, assemblies arises. The protocol described in this report provides a pathway to achieve such nanostructures through sequence-selective assemblies via dynamic covalent interactions.

\section{Disclosures}

The authors have nothing to disclose.

\section{Acknowledgments}

This work was supported by the U.S. Department of Energy, Office of Science, Basic Energy Sciences, under Award \#DESC0012479. S.C.L. acknowledges support from the National Science Foundation Graduate Research Fellowship Program, and A.F.A. acknowledges support from Abu Dhabi National Oil Company (ADNOC).

\section{References}

1. Seeman, N.C. Nucleic acid junctions and lattices. Journal of Theoretical Biology. 99 (2), 237-247 (1982).

2. Rothemund, P.W.K. Folding DNA to create nanoscale shapes and patterns. Nature. 440 (March), 297-302 (2006).

3. Watt, A.A.R., Bothma, J.P., Meredith, P. The supramolecular structure of melanin. Soft Matter. 5 (19), 3754-3760 (2009).

4. Tørring, T., Voigt, N. V., Nangreave, J., Yan, H., Gothelf, K. V. DNA origami: A quantum leap for self-assembly of complex structures. Chemical Society Reviews. 40 (12), 5636-5646 (2011).

5. Wei, B., Dai, M., Yin, P. Complex shapes self-assembled from single-stranded DNA tiles. Nature. 485 (7400), $623-626$ (2012).

6. Clausen-Schaumann, H., Rief, M., Tolksdorf, C., Gaub, H.E. Mechanical stability of single DNA molecules. Biophysical Journal. 78 (4), 1997-2007 (2000).

7. Rowan, S.J., Cantrill, S.J., Cousins, G.R.L., Sanders, J.K.M., Stoddart, J.F. Dynamic covalent chemistry. Angewandte Chemie - International Edition. 41 (6). (2002).

8. Jin, Y., Yu, C., Denman, R.J., Zhang, W. Recent advances in dynamic covalent chemistry. Chemical Society Reviews. 42 (16), $6634-6654$ (2013).

9. Furgal, J.C., Dunn, M., Wei, T., Scott, T.F. Emerging Applications of Dynamic Covalent Chemistry from Macro- to Nanoscopic Length Scales. Dynamic Covalent Chemistry: Principles, Reactions, and Applications. 389-434 (2017).

10. Hartley, C.S., Elliott, E.L., Moore, J.S. Covalent assembly of molecular ladders. Journal of the American Chemical Society. 129 (15), 4512-4513 (2007).

11. Wei, T., Furgal, J.C., Jung, J.H., Scott, T.F. Long, self-assembled molecular ladders by cooperative dynamic covalent reactions. Polymer Chemistry. 8 (3), 520-527 (2017).

12. Dunn, M.F., Wei, T., Scott, T.F., Zuckermann, R.N. Aqueous dynamic covalent assembly of molecular ladders and grids bearing boronate ester rungs. Polymer Chemistry. (18), 2337-2343 (2019).

13. Furgal, J.C., Dijck, J.M. Van, Leguizamon, S.C., Scott, T.F. Accessing sequence specific hybrid peptoid oligomers with varied pendant group spacing. European Polymer Journal. (118), 306-311 (2019).

14. Tozawa, T. et al. Porous organic cages. Nature Materials. 8 (12), 973-978 (2009).

15. Tian, J., Thallapally, P.K., Dalgarno, S.J., McGrail, P.B., Atwood, J.L. Amorphous molecular organic solids for gas adsorption. Angewandte Chemie - International Edition. 48 (30), 5492-5495 (2009). 
16. Jin, Y., Wang, Q., Taynton, P., Zhang, W. Dynamic covalent chemistry approaches toward macrocycles, molecular cages, and polymers. Accounts of Chemical Research. 47 (5), 1575-1586 (2014).

17. Ren, F., Day, K.J., Hartley, C.S. Two- and three-tiered stacked architectures by covalent assembly. Angew. Chem. Int. Ed. 55 (30), $8620-8623$ (2016).

18. Elliott, E.L., Hartley, C.S., Moore, J.S. Covalent ladder formation becomes kinetically trapped beyond four rungs. Chemical Communications. 47 (17), 5028-5030 (2011).

19. Tran, H., Gael, S.L., Connolly, M.D., Zuckermann, R.N. Solid-phase submonomer synthesis of peptoid polymers and their self-assembly into highly-ordered nanosheets. Journal of Visualized Experiments. (57), 1-6 (2011).

20. Zuckermann, R.N. Peptoid origins. Biopolymers. 96 (5), 545-555 (2011).

21. Sun, J., Zuckermann, R.N. Peptoid polymers: A highly designable bioinspired material. ACS Nano. 7 (6), $4715-4732$ (2013).

22. Belowich, M.E., Stoddart, J.F. Dynamic imine chemistry. Chemical Society Reviews. 41 (6), 2003-2024 (2012).

23. Giuseppone, N., Schmitt, J.L., Schwartz, E., Lehn, J.M. Scandium(III) catalysis of transimination reactions. Independent and constitutionally coupled reversible processes. Journal of the American Chemical Society. 127 (15), 5528-5539 (2005).

24. Shū, K. Scandium triflate in organic synthesis. European Journal of Organic Chemistry. 1999 (1), 15-27 (1999).

25. Wei, T., Furgal, J.C., Scott, T.F. In situ deprotection and dynamic covalent assembly using a dual role catalyst. Chemical Communications. $\mathbf{5 3}$ (27), 3874-3877 (2017)

26. Matsumoto, M. et al. Rapid, low temperature formation of imine-linked covalent organic frameworks catalyzed by metal triflates. Journal of the American Chemical Society. 139 (14), 4999-5002 (2017).

27. Ma, X., Scott, T.F. Approaches and challenges in the synthesis of three-dimensional covalent-organic frameworks. Communications Chemistry. In Press (2018).

28. Perron, V., Abbott, S., Moreau, N., Lee, D., Penney, C., Zacharie, B. A method for the selective protection of aromatic amines in the presence of aliphatic amines. Synthesis. (2), 283-289 (2009).

29. Wei, T., Jung, J.H., Scott, T.F. Dynamic covalent assembly of peptoid-based ladder oligomers by vernier templating. Journal of the American Chemical Society. 137 (51), 16196-16202 (2015).

30. Ouari, O., Chalier, F., Bonaly, R., Pucci, B., Tordo, P. Synthesis and spin-trapping behaviour of glycosylated nitrones. Journal of the Chemical Society, Perkin Transactions 2. (10), 2299-2308 (1998).

31. Sun, J., Stone, G.M., Balsara, N.P., Zuckermann, R.N. Structure-conductivity relationship for peptoid-based PEO-mimetic polymer electrolytes. Macromolecules. 45 (12), 5151-5156 (2012).

32. Sartori, G., Ballini, R., Bigi, F., Bosica, G., Maggi, R., Righi, P. Protection (and deprotection) of functional groups in organic synthesis by heterogeneous catalysis. Chemical Reviews. 104 (1), 199-250 (2004).

33. Kim, S. et al. Unusual truncation of N-acylated peptoids under acidic conditions. Organic \& biomolecular chemistry. 12 (28), $5222-6$ (2014)

34. Mannige, R. V. et al. Peptoid nanosheets exhibit a new secondary-structure motif. Nature. 526 (7573), 415-420 (2015).

35. Edison, J.R. et al. Conformations of peptoids in nanosheets result from the interplay of backbone energetics and intermolecular interactions. Proceedings of the National Academy of Sciences. 115 (22), 5647-5651 (2018).

36. Kobayashi, S., Sugiura, M., Kitagawa, H., Lam, W.W.L. Rare-earth metal triflates in organic synthesis. Chemical Reviews. 102 (6), $2227-2302$ (2002).

37. Fujinaga, S., Hashimito, M., Tsukagoshi, K. Investigation of the composition for a ternary solvent system in tube radial distribution chromatography. Journal of Liquid Chromatography and Related Technologies. 38 (5), 600-606 (2015). 